\section{Posterior reversible encephalopathy syndrome: differences between pregnant and non-pregnant patients}

\author{
Luiz Carlos Porcello Marrone, 1 \\ Giovani Gadonski, 2 \\ Luciano Passamani Diogo,1 \\ João Pedro Farina Brunelli,1 \\ William Alves Martins, \\ Gabriela de Oliveira Laguna, 1 \\ Laura Fuchs Bahlis, \\ João Rubião Hoefel Filho, 3 \\ Bartira Ercilia Pinheiro da Costa,2 \\ Carlos Eduardo Poli-de-Figueiredo, 2 \\ Antônio Carlos Huf Marrone, 1 \\ Jaderson Costa da Costa \\ 1Service of Neurology, 2Service of \\ Nephrology and 3Service of Radiology, \\ Instituto do Cérebro, Hospital São Lucas, \\ Pontifícia Universidade Católica do Rio \\ Grande do Sul, Porto Alegre, Brazil
}

\section{Abstract}

Posterior reversible encephalopathy syndrome (PRES) is a clinical-radiologic entity not yet understood, that presents with transient neurologic symptoms and particular radiological findings. Few papers show the differences between pregnant and non-pregnant patients. We review the cases of 38 women diagnosed with PRES, in order to find significant differences between pregnant (18) and non-pregnant (20) patients. We found differences among the age of patients (25.83 years old in pregnant and 29.31 years old in non pregnant; $\mathrm{P}=0.001$ ); in the mean of highest systolic blood pressure, that was higher in nonpregnant group (185:162 mmHg; $\mathrm{P}=0.121$ ); and in creatinine levels that was higher in non-pregnant group (3.47:1.04 $\mathrm{mg} / \mathrm{dL}$; $\mathrm{P}=0.001)$. To our knowledge, just a few papers analyzed whether PRES syndrome presented in the same way in pregnant and non-pregnant patients. The differences and the possible pathophisiology of this syndrome still remain enigmatic.

\section{Introduction}

Posterior reversible encephalopathy syndrome (PRES) is a clinicoradiologic entity characterized by headaches, altered mental status, seizures, and visual loss; it is associated with white matter vasogenic edema pre- dominantly affecting the occipital and parietal lobes of the brain. ${ }^{1}$ The cause of PRES is not yet understood. Auto-regulatory failure with resultant vasodilation, as seen in hypertensive encephalopathy, is often cited as the underlying mechanism. On the other hand, vasospasm with ischemic change is also observed in some patients.2,3

Several factors can trigger the syndrome, most commonly: acute elevation of blood pressure, abnormal renal function and immunosuppressive therapy. ${ }^{1}$ Other possible etiologies are eclampsia, ${ }^{4-7}$ transplantation, ${ }^{8}$ neoplasia and chemotherapy treatment, ${ }^{9}$ systemic infections, ${ }^{10}$ renal disease acute or chronic. ${ }^{11,12}$

The most characteristic imaging pattern in PRES is the presence of edema involving the white matter of the posterior portions of both cerebral hemispheres, especially the parietooccipital regions, in a relatively symmetric pattern that spares the calcarine and paramedian parts of the occipital lobes (Figure 1). ${ }^{1}$ However, other structures (such as the brain stem, cerebellum, and frontal and temporal lobes) may also be involved, and although the abnormality primarily affects the subcortical white matter, the cortex and the basal ganglia may also be involved. 13

Pre-eclampsia (PE) is one of the most common situations described in association with PRES. PE is a multisystem disorder that complicates $3-8 \%$ of pregnancies in Western countries,14,15 and has a complex pathophysiology. Defective invasion of the spiral arteries by cytotrophoblast cells is observed during preeclampsia. ${ }^{16}$ The crucial issue to understand is that the prime mover of PE is abnormal placentation. Two common theories appear to be interlinked, a genetic theory and an immunological theory. ${ }^{17}$ Clinical and laboratory tests are intended to define and determine the severity of PE. Headaches, tinnitus, visual disorders, brisk tendon reflexes, and vigilance disorders are related to cerebral edema; oliguria to acute renal failure; uterine contraction, vaginal bleeding to placental abruption; vomiting to HELLP syndrome (Hemolysis Elevated Liver enzymes Low Plaquet count); bandlike epigastric pain to subcapsular hepatic hematoma; and dyspnea to cardiac failure. Eclampsia, the major neurological complication of pre-eclampsia, is defined as a convulsive episode or any other sign of altered consciousness arising in a setting of $\mathrm{PE}$, and which cannot be attributed to a pre-existing neurological condition. Delivery is the only curative treatment for PE. 18

\section{Materials and Methods}

We realized a study on 38 cases of PRES (18
Correspondence: Luiz Carlos Porcello Marrone, Hospital São Lucas, Instituto do Cérebro, Pontifícia Universidade Católica do Rio Grande do Sul, Av. Ipiranga 6690, room 220, Porto Alegre, 90610-000 RS, Brazil.

Tel. +55.519.682.8472 - Fax: +55.513 .320 .5144$

E-mail: lcpmarrone@gmail.com

Key words: posterior reversible encephalopathy syndrome, reversible leukoencephalopathy, eclampsia/pre-eclampsia, brain magnetic resonance image, cerebral autoregulation.

Contributions: the authors contributed equally.

Conflict of interests: the authors declare no potential conflict of interests.

Received for publication: 28 February 2014.

Revision received: 6 March 2014.

Accepted for publication: 7 March 2014.

This work is licensed under a Creative Commons Attribution NonCommercial 3.0 License (CC BYNC 3.0).

(C) Copyright L.C. Porcello Marrone et al., 2014 Licensee PAGEPress, Italy

Neurology International 2014; 6:5376

doi:10.4081/ni.2014.5376

pregnant and 20 non-pregnant patients), that were admitted to the Neurologic Service of Hospital São Lucas-PUCRS (Brazil) or that were assisted in other units of the same hospital by our services. All the patients underwent a brain magnetic resonance image (MRI): 36 patients $(94.73 \%)$ were submitted to two brain MRI; 1 was submitted to one brain MRI plus one brain $\mathrm{CT}$; and the other one realized only one exam. The following data was evaluated: age, sex, previous diseases and past medical history, use of medications, the neurologic manifestations, the highest blood pressure during the neurologic presentation, the highest creatinine during the period of observation and the neuroimage alterations in brain MRI.

The highest blood pressure was measured during the 48 hours before the neurologic manifestation and the highest creatinine was analyzed during a mean period of two week before the neurologic manifestation. All the brain MRI were analyzed by a neurologist, who had no contact with the patient's clinical data. We analyzed the data using the Statistical Package for the Social Sciences (SPSS). We applied Chi-square test or Exact Fischer test for comparing data with non-parametic distribution and the Student $t$ test for comparison of means. A P value $<0.05$ was considered significant. All of the procedures and protocols executed in this study were approved by the Institutional Ethics Committee from Pontifícia Universidade Católica do Rio Grande do Sul. 


\section{Results}

It was performed a review of 38 cases of patients with the diagnosis of PRES, that were assisted in Hospital São Lucas-PUCRS. Among this 38 cases, with mean age 25.11 years old (range from 2 to 74 ) and $78.9 \%$ of female, there were three children, that were excluded of some analyzes. The children were excluded of analyze of the creatinine and blood pressure, because in our opinion, their age didn't premises us to include them in some evaluations (creatinine level and blood pressure). By the way, it was identified 34 patients (eighteen were pregnant or in puerperium period). The other group was composed by four patients with lupus, four with neoplasia in chemotherapy, ${ }^{9,19}$ four with glomerulonephritis, two patients with hypertension, two patients in use of Tacrolimus after renal transplantation, two patients with Hemolitic Uremic syndrome, one after scorpion sting and one patient with alteration of renal function. ${ }^{20}$

The mean age of the group of pregnant patients was 25.83 years old and was 29.31 years old in the other group. The group of nonpregnant patients was composed by five men and eleven women.

There was an important difference in the highest systolic blood pressure among both groups. In the non-pregnant group the mean highest systolic blood pressure was $185 \mathrm{mmHg}$ and in the pregnant group was $162 \mathrm{mmHg}$, but without statistical diference.

The mean creatinine was $3.47 \mathrm{mg} / \mathrm{dL}$ in the non-pregnant patients and was $1.04 \mathrm{mg} / \mathrm{dL}$ in the pregnant patients.

The most common symptom was headache in both groups $78.8 \%$ overall (reported by $88.9 \%$ of the pregnant patients and $70 \%$ of nonpregnant patients); followed by visual disturbance $65.8 \%$ overall $(66.7 \%$ of pregnant patients and $65 \%$ of non-pregnant patients); seizure $63.2 \%$ overall (50\% in pregnant group and $75 \%$ in non-pregnant group) and mental status alteration $(22 \%$ of pregnant patients and $52 \%$ of non-pregnant patients).

The alterations in all patients and the neuroimaging findings are described in Table 1.

\section{Discussion and Conclusions}

Since 1985, neuro-radiologic findings had been described in the presence of eclampsia and other pregnant dysfunctions. ${ }^{5}$ After its first description in 1996, many papers were published; however the precise pathophisiological mechanism remains unclear. ${ }^{1}$ In 2000 , Casey et al. proposer the term Posterior Reversible Encephalopathy Syndrome.21 Few papers analyzed if the syndrome presented in pregnant patients was the same described in the other patients with PRES.

In our group of patients, there was a difference in creatinine level; both of them with higher value in non-pregnant group. Even excluding the patient with renal disease (in case of creatinine level analyzes), the difference between the groups remains.

In 2009, Roth explored the differences between pregnant patients and non pregnant patients in a very interesting paper. Studying 21 patients, Roth described few differences in both groups, like headache was more reported by pregnant patients (87.5\%) than non-pregnant patients (30.8\%) and visual disturbance that was also more reported in pregnant patients than in non-pregnant patients $(75 \%$ vs $46.2 \%)$. In this study, the mean age of pregnant patients was 22 years old and was 49 years old in the group of non-pregnant patients. The blood pressures of both groups were very similar. ${ }^{22}$

Liman and colleagues performed the investigation of the mean arterial pressure in different groups of patients with PRES and found in infection (131 mmHg), auto-imunes disorders (123 mmHg), eclampsia (119 $\mathrm{mmHg}$ ) and chemotherapy $(110 \mathrm{mmHg}) .23$ Liman also reported that preeclampsia-eclampsia patients had significantly less severe edema, less cytotoxic edema, hemorrhage and contrast enhancement, while more frequent complete resolution of edema and less frequent residual structural lesions were seen on follow-up imaging. ${ }^{24}$ PRES is commonly seen in the setting of hypertension; probably due to a breakdown of autoregulation.

The autoregulation is an intrinsic function of the vasculature of the brain, designed to maintain a stable blood flow independent of

Table 1. Differences among pregnant and non-pregnant patients.

\begin{tabular}{lccc} 
& Pregnant & Non-Pregnant & P \\
Age & 25.83 & 29.31 & $0.001^{*}$ \\
Highest systolic blood pressure, $\mathrm{mmHg}{ }^{*}$ & 162 & 185 & 0.121 \\
\hline Patients systolic blood pressure $>160 \mathrm{mmHg}, \%$ & 66.7 & 81 & 0.308 \\
Patients systolic blood pressure $>180 \mathrm{mmHg}, \%$ & 16.7 & 61.9 & $0.004^{*}$ \\
\hline Highest creatinine, $\mathrm{mg} / \mathrm{dL}^{*}$ & 1.04 & 3.47 & $0.001^{*}$ \\
Headache (\%) & $88.9(16)$ & $70(14)$ & 0.154 \\
\hline Seizure (\%) & $50(9)$ & $75(15)$ & 0.111 \\
Visual disturbance (\%) & $66.7(12)$ & $65(13)$ & 0.914 \\
\hline Altered mental status (\%) & $22(4)$ & $55(11)$ & $0.039^{*}$ \\
Magnetic resonance findings (\%) & & & \\
$\quad$ Occipital & $83.3(15)$ & $100(20)$ & 0.057 \\
Parietal & $55.6(10)$ & $65(13)$ & 0.552 \\
Frontal & $27.8(5)$ & $30(6)$ & 0.565 \\
Temporal & $22.2(4)$ & $30(6)$ & 0.587 \\
\hline
\end{tabular}

*Patients with less than 12 years old were excluded of analysis.

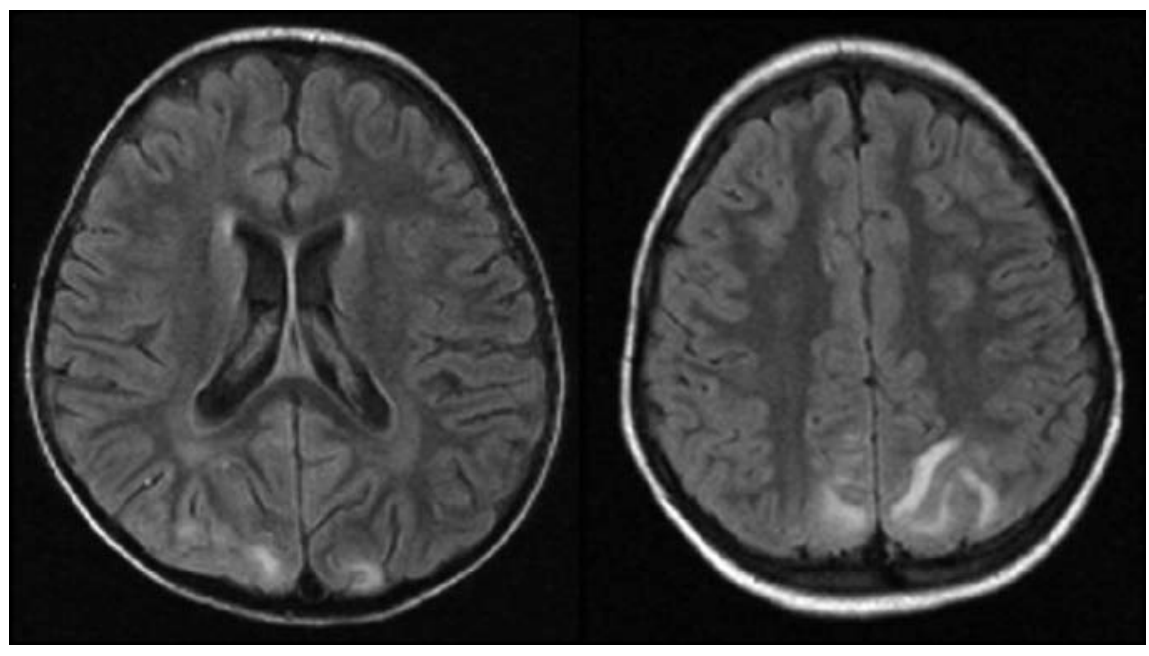

Figure 1. Brain magnetic resonance imaging (FLAIR) showing an increase of signal in both parieto-occipital lobes. 
the variation of blood pressure. In animal models, when a severe increase in blood pressure beyond the upper limit of autoregulation was caused, occur an arteriolar dilation, injury to the capillary bed, vasogenic edema and vessel injury with altered artery morphology. 25 The upper limits of autoregulation range among the patients. This limits depends primary on the capillary hydrostatic pressure, under the influence of the systolic blood pressure, the integrity of blood-brain barrier and other situations (like medications). ${ }^{26}$

Evaluating the differences of blood pressure among pregnant and non-pregnant patients, we demonstrated that pregnant patients present breakdown of cerebral autoregulation with lower mean arterial blood pressure. We speculate that the pregnant patients had different triggers of the other patients and the fact of the delivery is the curative treatment for PE can represent the finish of the stimulus for the brain vasogenic edema. Is it the reason that causes differences in the pregnant patients when compared with non-pregnant patients? This paper contributes showing differences of blood pressure and creatinine in this both groups. The precise pathophysiology mechanism of this syndrome remains enigmatic.

\section{References}

1. Hinchey J, Chaves C, Appignani B, et al. A reversible posterior leukoencephalopathy syndrome. N Engl J Med 1996;334:494-500.

2. Schwartz RB. Hyperperfusion encephalopathies: hypertensive encephalopathy and related conditions. Neurologist 2002;8:2234.

3. Bartynski WS, Boardman JF. Catheter angiography, MR angiography, and MR perfusion in posterior reversible encephalopathy syndrome. AJNR Am J Neuroradiol 2008;29:447-55.

4. Schwartz RB, Feske SK, Polak JF, et al. Preeclampsia-eclampsia: clinical and neuroradiographic correlates and insights into the pathogenesis of hypertensive encephalopathy. Radiology 2000;217:371-6.

5. Colosimo C Jr, Fileni A, Moschini M, Guerrini P. CT findings in eclampsia. Neuroradiology 1985;27:313-7.

6. Lewis LK, Hinshaw DB Jr, Will AD, et al. CT and angiographic correlation of severe neurological disease in toxemia of pregnancy. Neuroradiology 1988;30:59-64.

7. Naheedy MH, Biller J, Schiffer M, et al. Toxemia of pregnancy: cerebral CT findings. J Comput Assist Tomogr 1985;9:497501.

8. Bartynski WS, Tan HP, Boardman JF, et al. Posterior reversible encephalopathy syndrome after solid organ transplantation. AJNR Am J Neuroradiol 2008;29:924-30.

9. Marrone LC, Marrone BF, Raya JP, et. al Gemcitabine monotherapy associated with posterior reversible encephalopathy syndrome. Case Rep Oncol 2011;4:82-7.

10. Bartynski WS, Boardman JF, Zeigler ZR, et al. Posterior reversible encephalopathy syndrome in infection, sepsis, and shock. AJNR Am J Neuroradiol 2006;27:2179-90.

11. Onder AM, Lopez R, Teomete U, et al. Posterior reversible encephalopathy syndrome in the pediatric renal population. Pediatr Nephrol 2007;22:1921-9.

12. Gokce M, Dogan E, Nacitarhan S, Demirpolat G. Posterior reversible encephalopathy syndrome caused by hypertensive encephalopathy and acute uremia. Neurocrit Care 2006;4:133-6.

13. Lamy C, Oppenheim C, Méder JF, Mas JL. Neuroimaging in posterior reversible encephalopathy syndrome. J Neuroimaging 2004;14:89-96.

14. Carty DM, Delles C, Dominiczak AF. Preeclampsia and future maternal health. J Hypertens 2010;28:1349-55.

15. Duley L. The global impact of pre-eclampsia and eclampsia. Semin Perinatol 2009; 33:130-7.

16. Fisher SJ, McMaster M, Roberts M, eds. The placenta in normal pregnancy and preeclampsia. In: Chesley's hypertensive disorders in pregnancy. Amsterdam:
Academic Press, Elsevier; 2009.

17. Mutze S, Rudnik-Schoneborn S, Zerres K, Rath W. Genes and the preeclampsia syndrome. J Perinat Med 2008;36:38-58.

18. Uzan J, Carbonnel M, Piconne 0, et al. Preeclampsia: pathophysiology, diagnosis, and management. Vasc Health Risk Manag 2011;7:467-74.

19. Porcello Marrone LC, Marrone BF, Pascoal TA, et al. Posterior reversible encephalopathy syndrome associated with FOLFOX Chemotherapy. Case Rep Oncol Med 2013;2013:306983.

20. Porcello Marrone LC, Fontana Marrone B, Kalil Neto F, et al. Posterior reversible encephalopathy syndrome following a scorpion sting. J Neuroimaging 2013;23: 535-6.

21. Casey So, Sampaio RC, Michel E, Truwit CL. Posterior reversible encephalopathy syndrome: utility of fluid-attenuated inversion recovery MR imaging in the detection of cortical and subcortical lesions. AJNR Am J Neuroradiol 2000;21:1199-06.

22. Roth C, Ferbert A. Posterior reversible encephalopathy syndrome: is there a difference between pregnant and non-pregnant patients? Eur Neurol 2009;62:142-8.

23. Liman TG, Bohner G, Heuschmann PU, et al. The clinical and radiological spectrum of posterior reversible encephalopathy syndrome: the retrospective Berlin PRES study. J Neurol 2012;259:155-64.

24. Liman TG, Bohner G, Heuschmann PU, et al. Clinical and radiological differences in posterior reversible encephalopathy syndrome between patients with preeclampsia-eclampsia and other predisposing diseases. Eur J Neurol 2012;19:935-43.

25. Auer LM. The pathogenisis of hypertensive encephalopathy: experimental data and their clinical relevance with special reference to neurosurgical patients. Acta Neurochir Suppl (Wien) 1978;27:1-111.

26. Feske SK. Posterior reversible encephalopathy syndrome: a review. Semin Neurol 2011;31:202-15. 